\title{
PENGARUH WORD OF MOUTH (WOM), VISUAL MERCHANDISING DAN CREATIVE PROMOTION TERHADAP IMPULSE BUYING MINYAK KUTUS- KUTUS DI DENPASAR
}

\author{
aPande Wiguna, bNi Wayan Wijayanti \\ ${ }^{a, b}$ Fakultas Ekonomi dan Bisnis, Universitas Pendidikan Nasional (Undiknas) Denpasar \\ apandeewiguna@gmail.com
}

\begin{abstract}
ABSTRAK
Pengaruh Word of Mount (WOM), Visual Marchandising dan Creative Promotion Terhadap Impulse Buying Minyak Kutus-Kutus di Denpasar. Penelitian ini bertujuan untuk mengetahui pengaruh word of mouth, visual merchandising, dan creative promotion secara parsial dan simultan terhadap impulse buying. Penelitian ini dilakukan pada konsumen minyak kutus-kutus di Kota Denpasar. Jenis data yang digunakan dalam penelitian ini adalah data kuantitatif. Untuk memperoleh data dalam penelitian ini dilakukan dengan menyebarkan kuisioner. Jumlah indikator penelitian sebanyak 17 item. Sehingga jumlah sampel dalam penelitian ini adalah 85. Teknik analisis data yang digunakan dalam penelitian ini adalah analisis regresi linier berganda dengan bantuan SPSS for windows 23.0. Hasil uji t dalam penelitian ini yaitu word of mouth 0.046, visual merchandising sebesar 0.000, dan creative promotion sebesar 0.000 ini menunjukkan bahwa secara parsial ketiga variabel tersebut berpengaruh positif dan signifikan terhadap impulse buying. Hasil uji $f$ dalam penelitian ini yaitu sebesar 0.000 yang artinya secara simultan variabel word of mouth, visual merchandising, dan creative promotion berpengaruh positif dan signifikan terhadap impulse buying.
\end{abstract}

Kata kunci: word of mouth, visual merchandising, creative promotion, dan impulse buying

\begin{abstract}
The Influence of Word of Mouth, Visual Merchandising and Creative Promotion, on Impulse Buying Minyak Kutus-Kutus in Denpasar. This study aims to determine the effect of word of mouth, visual merchandising, and creative promotion partially and simultaneously on impulse buying. This research was carried out on consumers of cider oil in the city of Denpasar. The type of data used in this study is quantitative data. To obtain data in this study was conducted by distributing questionnaires. The number of research indicators is 17 items. So the number of samples in this study is 85 . The technique of analyzing the data used in this study is multiple linear regression analysis with statistical package for social science (SPSS) for Windows 23.0. The results of the $t$ test in this study are 0.046 word of mouth, visual merchandising of 0.000 , and creative promotion of 0.000 shows that partially the three variables have a positive and significant effect on impulse buying. The results of the $f$ test in this study are 0,000 which means that simultaneously word of mouth, visual merchandising, and creative promotion variables have a positive and significant effect on impulse buying.
\end{abstract}

Keywords: word of mouth, visual merchandising, creative promotion, dan impulse buying 


\section{PENDAHULUAN}

Di era globalisasi saat ini tingkat persaingan usaha bisnis sangatlah ketat termasuk di Indonesia. Dengan perkembangan teknologi yang sangat pesat, perusahaan mulai meningkatkan kualitas produk dan manajemen pemasaran untuk memenuhi tujuan memaksimalkan keuntungan seusai target perusahaan. Menurut (Hasan, 2010), word of mouth merupakan pujian, rekomendasi dan komentar pelanggan sekitar pengalaman mereka atas layanan jasa dan produk yang betul-betul memengaruhi keputusan pelanggan atau perilaku pembelian mereka. Jika informasi yang didapat konsumen bersifat positif maka dapat mempengaruhi proses Impulse Buying. Tampilan produk juga menjadi pertimbangan konsumen dalam melakukan pembelian. Promosi yang kreatif menggunakan strategi komunikasi pemasaran terpadu yaitu suatu sinergi, kreativitas, integrasi, dan komunikasi pemasaran dengan cara memanfaatkan beragam elemen komunikasi yang berbeda-beda agar tercipta koherensi yang saling mendukung (Freddy Rangkuti, 2009)

Minyak Kutus-Kutus merupakan obat herbal yang paling banyak dicari oleh masyarakat maupun pengguna obat herbal, karena memang khasiatnya yang telah terbukti.

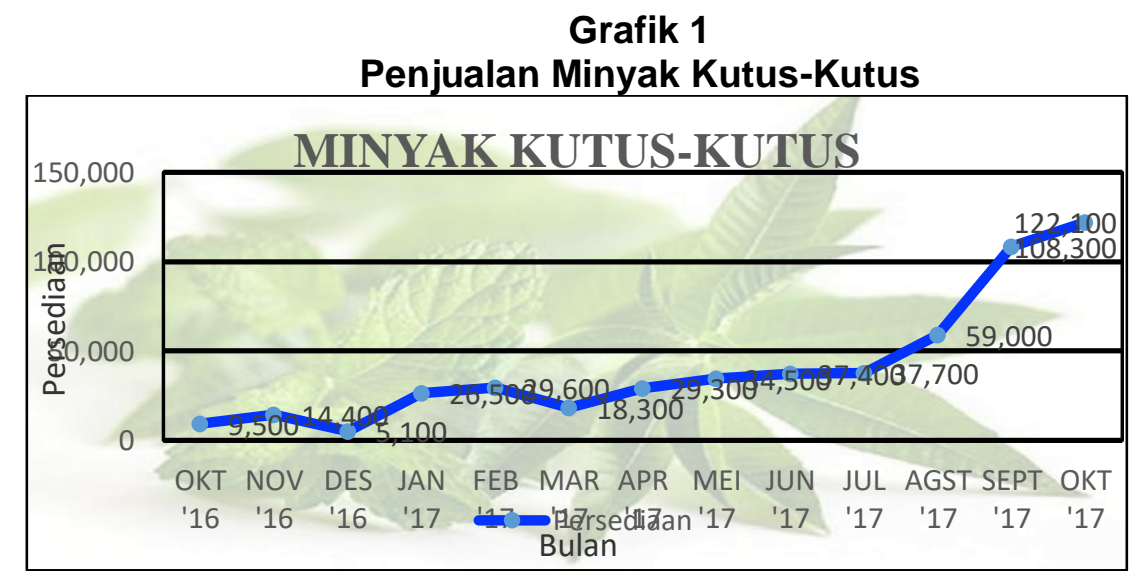

Sumber : minyakkutuskutus.me

Pada grafik 1 penjualan minyak Kutus-Kutus mengalami ketidak stabilan. Pada bulan Oktober 2016 hingga bulan Juni 2017 penjualan dari minyak Kutus-Kutus ini mengalami ketidak stabilan, sedangkan pada bulan berikutnya yaitu pada bulan Juli 2017 hingga Oktober 2017 mengalami peningkatan. Faktor yang menyebabkan minyak Kutus-Kutus tidak stabil diantaranya promosi yang kurang, dari pihak pihak pabrik sudah menekankan para distributor maupun resellernya untuk melakukan promosi sebanyak mungkin, agar para konsumen mendapatkan informasi yang jelas dan memanfaatkan komsumen untuk menawarkan atau mempromosikan kembali minyak herbal yang sudah digunakan dengan cara promosi dari mulut ke mulut kepada rekan, sahabat maupun keluarga atau yang lainnya. Penurunan penjualan minyak kutus-kutus ini disebabkan karena penyediaan produk sangat terbatas. Orderan yang diterima sudah melebihi batas produk yang tersedia. Hal ini disebabkan karena faktor cuaca, contohnya seperti bahan baku biji nyamplung, biji nyamplung ini hanya panen pada saat musim hujan.

\section{Tujuan Penelitian}

1. Untuk mengetahui pengaruh Word Of Mouth (WOM), Visual Merchandising, dan Creative Promotion berpengaruh secara parsial terhadap Impulse Buying Minyak Kutus-Kutus Di Denpasar.

2. Untuk mengetahui pengaruh Word Of Mouth (WOM), Visual Merchandising, dan Creative Promotion berpengaruh secara simultan terhadap Impulse Buying Minyak Kutus-Kutus Di Denpasar. 


\section{KAJIAN LITERATUR}

\section{Word Of Mouth}

Menurut (Hasan, 2010), Word Of Mouth merupakan pujian, rekomendasi dan komentar pelanggan sekitar pengalaman mereka atas layanan jasa dan produk yang betul-betul memengaruhi keputusan pelanggan atau perilaku pembelian mereka.

\section{Visual Merchandising}

Visual merchandising ialah teknik dalam mem-presentasikan tampilan barang dagangan sangat me-narik (eye-catching) dan ditujukan pada pelanggan potensial (Jain et al., 2012).

\section{Creative Promotion}

Promosi yang kreatif menggunakan strategi komunikasi pemasaran terpadu yaitu suatu sinergi, kreativitas, integrasi, dan komunikasi pemasaran dengan cara memanfaatkan beragam elemen komunikasi yang berbeda-beda agar tercipta koherensi yang saling mendukung (Freddy Rangkuti, 2009).

\section{Impulse Buying}

Impulse Buying merupakan keputusan konsumen tentang apa yang hendak dibeli, dimana akan dilakukan, kapan akan dilakukan dan bagaimana pembelian akan dilakukan (Engel, 2000).

\section{Kerangka Pemikiran}

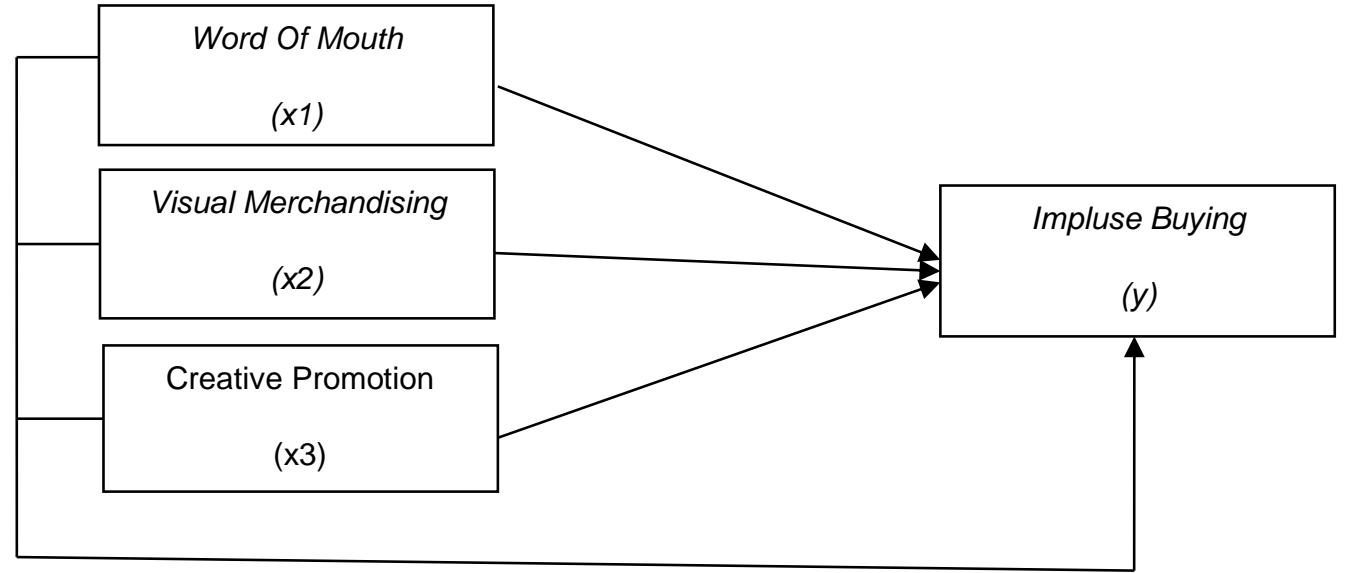

\section{Hipotesis Penelitian}

$\mathrm{H} 1$ : Secara parsial Word Of Mouth berpengaruh positif terhadap Impulse Buying.

H2: Secara parsial Visual Merchandising berpengaruh positif terhadap Impulse Buying.

H3: Secara parsial Creative Promotion berpengaruh positif terhadap Impulse Buying

H4: Secara simultan Word Of Mouth, Visual Merchandisin dan Creative Promotion berpengaruh positif terhadap Impulse Buying.

\section{METODE}

\section{Lokasi Penelitian}

Penelitian ini di lakukan di jalan Kenyeri II No. 8, Denpasar Timur, Bali 80239.

\section{Populasi dan Sampel}

Populasi dalam penelitian ini adalah seluruh pembeli Minyak Kutus-Kutus dengan jumlah populasinya yang belum dapat ditentukan. Teknik pengambilan sampel yang digunakan 
adalah non probability sampling dengan pendekatan purposive sampling yaitu peneliti memilih sampel purposive secara subyektif (Ferdinand, 2006). Calon responden harus memiliki kriteria tertentu yaitu, responden yang dipilih merupakan konsumen yang membeli produk minyak Kutus-Kutus di Denpasar untuk kedua kalinya.

Menurut Ferdinand (2006) menyatakan bahwa bila ukuran sampel terlalu besar maka model menjadi sangat sensitive sehingga sulit untuk mendapatkan goodness of fit yang baik. Untuk itu didasarkan ukuran sampel adalah 5-10 kali jumlah indikator dari keseluruhan variabel. Dalam penelitian ini, jumlah indikator penelitian sebanyak 16 item. Sehingga jumlah sampel minimum 5 kali jumlah indikator atau sebanyak $5 \times 17=85$, untuk itu dalam penelitian ini menggunakan sampel 85.

\section{Jenis Data}

Jenis data yang digunakan dalam penelitian ini adalah data kuantitatif. Data kuantitatif adalah data yang berbentuk angka seperti hasil dari kuesioner yang diberikan kepada pembeli Minyak Kutus - Kutus.

\section{Sumber Data}

Sumber data dalam penelitian ini adalah data primer dan data sekunder. Data primer dalam penelitian ini didapat langsung dari kuisioner yang diberikan kepada para pembeli Minyak Kutus - Kutus di Kota Denpasar. Data sekunder dalam penelitian ini didapat dari berbagai sumber bacaan seperti buku, jurnal, laporan dari penelitian terdahulu, maupun media informasi lainnya.

\section{Teknik Pengumpulan Data}

Teknik pengumpulan data dalam penelitian ini dilakukan dengan menyebarkan kuisioner. Dalam kuesioner pembobotan nilai dilakukan dengan menggunakan skala likert, dimana responden menentukan tingkat persetujuan mereka terhadap suatu pertanyaan atau pernyataan dengan memilih salah satu dari pilihan yang tersedia.

\section{Instrumen Penelitian dan Pengujiannya Uji Validitas}

Uji validitas digunakan untuk mengukur valid tidaknya suatu kuisioner. Menurut (Sugiyono 2016) Valid berarti instrumen tersebut dapat digunakan untuk mengukur apa yang seharusnya diukur.

\section{Uji Reliabilitas}

Reliabilitas merupakan alat untuk mengukur sejauh mana alat ukur yang digunakan dapat dipercaya. Penelitian ini menggunakan bantuan aplikasi SPSS Versi 17 dengan teknik uji alpha cronbach. Teknik ini dapat digunakan untuk menentukan apakah suatu instrumen penelitian reliabel atau tidak.SPSS memberikan fasilitas untuk mengukur reliabilitas dengan uji statistic Cronbach Alpha (a). (Ghozali 2011) menyatakan suatu variabel dikatakan reliabel jika memberikan nilai $(\alpha) 0,60$.

\section{Teknik Analisis Data \\ Uji Asumsi Klasik}

1) Uji Normalitas

Uji normalitas adalah uji yang dilakukan untuk mengetahui apakah data berdistribusi secara normal atau tidak.

\section{2) Uji Multikolinieritas}

Uji multikolinearitas bertujuan untuk menguji apakah ada korelasi antara sesama variabel independen yang digunakan dalam model persamaan regresi.

3) Uji Heteroskedastisitas

Uji heteroskedastisitas menguji terjadinya perbedaan variance residual suatu periode pengamatan ke periode pengamatan yang lain.

\section{4) Uji Analisis Regresi Linier Berganda}


Analisis regresi linier berganda digunakan untuk mengetahui ada tidaknya pengaruh Word Of Mouth, Visual Merchandising dan Creative Promotion. terhadap Impulse Buying produk minyak kutus-kutus.

\section{Koefisien Determinasi}

Koefisien determinasi digunakan untuk mengetahui kekuatan variasi hubungan antara word of mouth, visual merchandising, dan creative promotion terhadap impulse buying produk minyak Kutus-Kutus yang dinyatakan dalam persentase.

\section{Uji Regresi secara Parsial (uji t)}

Pengujian ini dilakukan untuk mengetahui tingkat signifikansi pengaruh variabel bebas yaitu perubahan Word Of Mouth, Visual Merchandising dan Creative Promotion secara parsial terhadap perubahan Impulse Buying pada produk Minyak Kutus-Kutus.

\section{Uji Regresi secara Simultan (Uji F)}

Pengujian ini dilakukan untuk mengetahui tingkat signifikansi pengaruh variabel bebas yaitu perubahan Word Of Mouth, Visual Merchandising dan Creative Promotionsecara simultan terhadap Impulse Buying pada produk Minyak Kutus-Kutus.

\section{HASIL DAN PEMBAHASAN}

\section{Deskripsi Responden Penelitian}

Berdasarkan data dari 85 responden yang mengisi kuesioner pada penelitian ini diperoleh karakteristik responden yang terdiri dari usia, jenis kelamin, dan pekerjaan sebagai berikut:

\section{Tabel 1}

\section{Deskripsi Responden}

\begin{tabular}{|l|l|l|}
\hline Keterangan & Jumlah Responden & Persentase (\%) \\
\hline Usia & 38 & \\
1. Dibawah 30 tahun & 47 & $44,7 \%$ \\
2. Diatas 31 tahun & 85 & $55,3 \%$ \\
\hline Jumlah & & $100 \%$ \\
\hline Jenis Kelamin & 20 & \\
1. Laki-laki & 65 & $23,5 \%$ \\
2. Perempuan & 85 & $76,5 \%$ \\
\hline Jumlah & & $100 \%$ \\
\hline Pekerjaan & 17 & \\
1. Mahasiswa & 13 & $20,0 \%$ \\
2. PNS & 0 & $15,3 \%$ \\
3. Polri & 0 & $00,0 \%$ \\
4. Tentara & 20 & $00,0 \%$ \\
5. Wiraswasta & 2 & $23,5 \%$ \\
6. Dokter & 15 & $2,4 \%$ \\
7. Guru & 18 & $17,6 \%$ \\
8. Lainnya & 85 & $21,2 \%$ \\
\hline Jumlah & & $100 \%$ \\
\hline
\end{tabular}

Sumber: Data Primer yang diolah, 2018 


\section{Instrumen Penelitian dan Pengujiannya Uji Validitas}

Tabel 2

Rekapitulasi Hasil Uji Validitas

\begin{tabular}{|l|l|l|l|}
\hline \multirow{3}{*}{ Variabel } & \multirow{2}{*}{ Item } & Validitas & \\
\cline { 3 - 4 } & & $\begin{array}{l}\text { Koefisien } \\
\text { Korelasi }\end{array}$ & Keterangan \\
\hline Word Of Mouth (WOM) (X1) & $\mathrm{X} 1.1$ & 0,699 & Valid \\
\cline { 2 - 4 } & $\mathrm{X} 1.2$ & 0,642 & Valid \\
\cline { 2 - 4 } & $\mathrm{X} 1.3$ & 0,828 & Valid \\
\cline { 2 - 4 } & $\mathrm{X} 1.4$ & 0,809 & Valid \\
\hline Visual Merhandising (X2) & $\mathrm{X} 2.1$ & 0,780 & Valid \\
\cline { 2 - 4 } & $\mathrm{X} 2.2$ & 0,847 & Valid \\
\cline { 2 - 4 } & $\mathrm{X} 2.3$ & 0,913 & Valid \\
\cline { 2 - 4 } & $\mathrm{X} 2.4$ & 0,881 & Valid \\
\hline Creative Promotion (X3) & $\mathrm{X} 3.1$ & 0,871 & Valid \\
\cline { 2 - 4 } & $\mathrm{X} 3.2$ & 0,916 & Valid \\
\cline { 2 - 4 } & $\mathrm{X} 3.3$ & 0,895 & Valid \\
\cline { 2 - 4 } & $\mathrm{X} 3.4$ & 0,771 & Valid \\
\hline Impulse Buying (Y) & $\mathrm{Y} 1.1$ & 0,738 & Valid \\
\cline { 2 - 4 } & $\mathrm{Y} 1.2$ & 0,757 & Valid \\
\cline { 2 - 4 } & $\mathrm{Y} 1.3$ & 0,725 & Valid \\
\cline { 2 - 4 } & $\mathrm{Y} 1.4$ & 0,614 & Valid \\
\cline { 2 - 4 } & $\mathrm{Y} 1.5$ & 0,533 & Valid \\
\hline
\end{tabular}

Sumber: Data diolah (2018)

Dapat dilihat hasil dari uji pada tabel 2 menunjukkan bahwa semua pertanyaan mempunyai koefisien lebih besar dari 0,3 sehingga semua instrumen yang digunakan dalam penelitian ini dinyatakan valid.

Tabel 3

Hasil Uji Reliabilitas

\begin{tabular}{|l|l|l|}
\hline Variabel & $\begin{array}{l}\text { Cronbach's } \\
\text { Alpha }\end{array}$ & Keterangan \\
\hline Word Of Mouth (WOM) $(\mathrm{X} 1)$ & 0.798 & Reliabel \\
\hline Visual Merhandising (X2) & 0.830 & Reliabel \\
\hline Creative Promotion (X3) & 0.833 & Reliabel \\
\hline Impulse Buying (Y) & 0.767 & Reliabel \\
\hline
\end{tabular}

Sumber: Data diolah (2018)

Suatu konstruk atau variabel dikatakan reliabel jika besarnya nilai Cronbach's Alpha lebih dari 0,70 (Ghozali, 2016). Berdasarkan tabel 3 maka dapat diketahui bahwa instrumen penelitian dari semua variabel dinyatakan reliabel karena memiliki koefisien reliabilitas lebih besar dari 0,70 . Hal ini menunjukkan bahwa pengukuran tersebut dapat memberi hasil yang konsisten, apabila dilakukan pengukuran kembali terhadap subjek yang sama. 


\section{Uji Asumsi Klasik \\ Uji Normalitas}

Tabel 4

Uji Normalitas dengan Uji Kolmogorov-Smirnov

One-Sample Kolmogorov-Smirnov Test

\begin{tabular}{|c|c|c|}
\hline & & Unstandardized Residual \\
\hline N & & 85 \\
\hline \multirow[t]{2}{*}{ Normal Parameters ${ }^{\mathrm{a}, \mathrm{b}}$} & Mean & 0.0000000 \\
\hline & Std. Deviation & 1.07127962 \\
\hline \multirow[t]{3}{*}{ Most Extreme Differences } & Absolute & 0.111 \\
\hline & Positive & 0.070 \\
\hline & Negative & -0.111 \\
\hline Kolmogorov-Smirnov Z & & 1.024 \\
\hline Asymp. Sig. (2-tailed) & & 0.246 \\
\hline
\end{tabular}

a. Test distribution is Normal.

b. Calculated from data.

Sumber: Data diolah (2018)

Berdasarkan Tabel 4 diatas, hasil yang didapatkan dengan menggunakan Uji KolmogorovSmirnov memiliki tingkat signifikansi sebesar 0,246 > 0,05 sehingga dapat dikatakan bahwa data berdistribusi secara normal.

\section{Uji Multikolonearitas}

Tabel 5

Hasil Uji Multikolonearitas

\begin{tabular}{|l|c|c|}
\hline \multirow{2}{*}{ del } & \multicolumn{2}{|c|}{ Collenearity Statistic } \\
\cline { 2 - 3 } & Ierance & \\
\hline Word Of Mouth (WOM) (X1) & 0,930 & 1,075 \\
\hline Visual Merhandising (X2) & 0,907 & 1,103 \\
\hline Creative Promotion (X3) & 0,973 & 1,028 \\
\hline
\end{tabular}

Sumber: Data diolah (2018)

Dari tabel 5 tersebut dapat dilihat bahwa nilai tolerance masing-masing variabel lebih besar dari 0,10 dan nilai VIF masing-masing variabel dibawah 10, sehingga dapat disimpulkan bahwa tidak terjadi hubungan multikolonearitas dalam model regresi.

\section{Uji Heteroskedastisitas}

Analisis pada gambar Scatterplot yang menyatakan model regresi linear berganda tidak terdapat heteroskedastisitas jika:

a. Titik-titik data menyebar di atas, di bawah, atau di sekitar angka nol.

b. Titik-titik data tidak mengumpul hanya di atas atau di bawah saja.

c. Penyebaran titik-titik data tidak boleh membentuk pola bergelombang melebar kemudian menyempit dan melebar kembali.

d. Penyebaran titik-titik data sebaiknya tidak berpola. 
Scatterplot

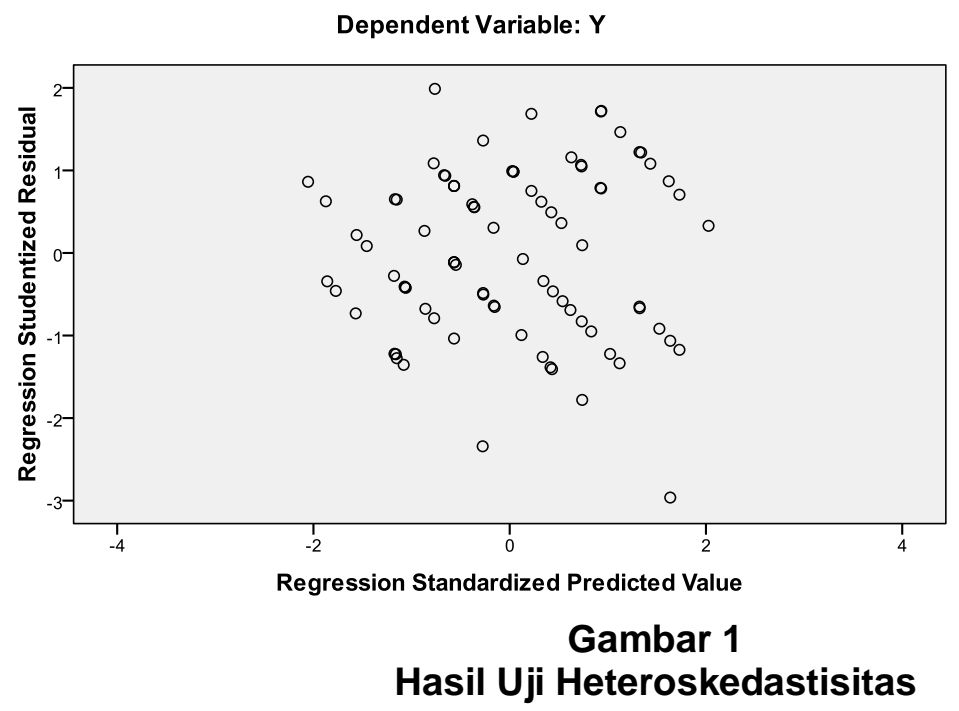

Sumber: Data diolah (2018)

Dari gambar 1 menunjukkan bahwa data tersebar secara acak dan tidak ada pola yang jelas, serta titik-titik menyebar diatas dan dibawah angka 0 (nol) pada sumbu Y, sehingga dapat disimpulkan bahwa tidak terjadi heteroskedastisitas.

\section{Hasil Uji Regresi Linier Berganda}

Tabel 6

Hasil Uji Regresi Linear Berganda

Coefficients $^{\mathrm{a}}$

\begin{tabular}{|c|c|c|c|c|c|c|}
\hline & & \multicolumn{2}{|c|}{$\begin{array}{l}\text { Unstandardized } \\
\text { Coefficients }\end{array}$} & \multirow{2}{*}{\begin{tabular}{|l} 
Standardized \\
Coefficients \\
Beta \\
\end{tabular}} & \multirow[b]{2}{*}{ t } & \multirow[b]{2}{*}{ Sig. } \\
\hline \multicolumn{2}{|c|}{ Model } & $B$ & Std. Error & & & \\
\hline \multirow[t]{4}{*}{1} & (Constant) & 5,896 & 1,560 & & 3,781 & 0,000 \\
\hline & $\mathrm{X} 1$ & 0,138 & 0,068 & 0,144 & 2,025 & 0,046 \\
\hline & $\mathrm{X} 2$ & 0,410 & 0,059 & 0,497 & 6,892 & 0,000 \\
\hline & X3 & 0,404 & 0,058 & 0,486 & 6,979 & 0,000 \\
\hline
\end{tabular}

Sumber: Data diolah (2018)

Pada tabel 6 terlihat nilai koefisien konstanta $(a)=5,896$; koefisien Word OF Mouth $\left(b_{1}\right)=$ 0,138; koefisien Visual Merchandising $\left(b_{2}\right)=0,410$; dan koefisien Creative Promotion $\left(b_{3}\right)=$ 0,404 . Dengan demikian dapat dibuat persamaan regresi linear berganda sebagai berikut:

$$
\begin{gathered}
Y=a+b_{1} X_{1}+b_{2} X_{2}+b_{3} X_{3}+e \\
Y=5,896+0,144 X_{1}+0,497 X_{2}+0,486 X_{3}
\end{gathered}
$$




\section{Uji Koefisien Determinasi}

\section{Tabel 7 \\ Hasil Uji Keofisien Determinasi}

Model Summary

\begin{tabular}{|l|l|l|l|l|}
\hline Model & $R$ & R Square & Adjusted R Square & $\begin{array}{l}\text { Std. Error of the } \\
\text { Estimate }\end{array}$ \\
\hline 1 & $0,786^{\mathrm{a}}$ & 0,618 & 0,603 & 1,09094 \\
\hline
\end{tabular}

a. Predictors: (Constant), X3, X1, X2

b. Dependent Variable: $Y$

Sumber: data diolah (2018)

Berdasarkan pada tabel 7 hasil pengujian koefisien determinasi (R2) diperoleh besarnya $R$ Square sebesar 0,618, hal ini mengindikasikan sebesar $61,8 \%$ Impulse Buying (variabel dependen) dapat dijelaskan oleh Word Of Mouth, Visual Merchandising, dan Creative Promotion (variabel independen), sedangkan 38,2\% lainnya ditentukan atau dipengaruhi oleh variabel dan faktor lain yang tidak terdeteksi dalam penelitian ini.

\section{Uji Regresi secara Parsial (Uji t)}

\section{Tabel 8}

Hasil Uji Regresi Secara Parsial (Uji t)

Coefficients $^{\mathrm{a}}$

\begin{tabular}{|c|c|c|c|c|c|c|}
\hline & & \multicolumn{2}{|c|}{$\begin{array}{l}\text { Unstandardized } \\
\text { Coefficients }\end{array}$} & $\begin{array}{l}\text { Standardized } \\
\text { Coefficients }\end{array}$ & \multirow[b]{2}{*}{$\mathrm{t}$} & \multirow[b]{2}{*}{ Sig. } \\
\hline \multicolumn{2}{|c|}{ Model } & $B$ & Std. Error & Beta & & \\
\hline \multirow[t]{4}{*}{1} & (Constant) & 5,896 & 1,560 & & 3,781 & 0,000 \\
\hline & $\mathrm{X} 1$ & 0,138 & 0,068 & 0,144 & 2,025 & 0,046 \\
\hline & $\mathrm{X} 2$ & 0,410 & 0,059 & 0,497 & 6,892 & 0,000 \\
\hline & X3 & 0,404 & 0,058 & 0,486 & 6,979 & 0,000 \\
\hline
\end{tabular}

Sumber: data diolah (2018)

1. Pengaruh Word Of Mouth (X1) terhadap Impulse Buying $(\mathrm{Y})$

Hasil uji statistik t yang diperoleh Word Of Mouth memiliki tingkat signifikansi sebesar $0,046<0,05$. Dari hasil uji statistik tersebut, maka hipotesis pertama yang menyatakan Word Of Mouth secara parsial berpengaruh positif terhadap Impulse Buying dapat diterima ( $\mathrm{H} 1$ diterima).

2. Pengaruh Visual Merchandising (X2) terhadap Impulse Buying (Y)

Hasil uji statistik $t$ yang diperoleh Visual Merchandising memiliki tingkat signifikansi sebesar $0,000<0,05$. Dari hasil uji statistik tersebut, maka hipotesis kedua yang menyatakan Visual Merchandising secara parsial berpengaruh positif terhadap Impulse Buying dapat diterima ( $\mathrm{H} 2$ diterima).

3. Pengaruh Creative Promotion (X3) terhadap Impulse Buying (Y)

Hasil uji statistik t yang diperoleh Creative Promotion memiliki tingkat signifikansi sebesar $0,000<0,05$. Dari hasil uji statistik tersebut, maka hipotesis ketiga yang menyatakan Creative Promotion secara parsial berpengaruh positif terhadap Impulse Buying dapat diterima (H3 diterima). 
Uji Regresi secara Simultan (Uji F)

\section{Tabel 9 \\ Hasil Uji Regresi Secara Simultan (Uji F)}

ANOV A $^{\text {b }}$
\begin{tabular}{|l|l|l|l|l|l|}
\hline Model & Sum of Squares & Df & Mean Square & F & Sig. \\
\hline 1 Regression & 155,645 & 3 & 51,882 & 43,593 & $0,000^{\text {a }}$ \\
Residual & 96,402 & 81 & 1,190 & & \\
Total & 252,047 & 84 & & & \\
\hline
\end{tabular}

a. Predictors: (Constant), X3, X1, X2

b. Dependent Variable: $Y$

Sumber: data diolah (2018)

Berdasarkan Tabel 9 diatas, uji signifikansi dilakukan dengan membandingkan nilai probabilitas signifikansi dengan nilai pada tingkat signifikansi yang telah ditentukan yaitu sebesar $0,000<0,05$. Ini berarti bahwa model regresi layak digunakan (model fit).

\section{Pembahasan}

1) Pengaruh Word Of Mouth Secara Parsial Terhadap Impulse Buying pada produk Minyak Kutus-Kutus di Denpasar

Berdasarkan Tabel dapat diketahui pengaruh Word Of Mouth secara parsial terhadap Impulse Buying menghasilkan nilai signifikansi $0,046<0,05$ dengan nilai koefisien beta positif. Hasil tersebut mendukung hipotesis $(\mathrm{H} 1)$ yaitu Secara parsial Word Of Mouth berpengaruh positif terhadap Impulse Buying. Hal ini berarti bahwa semakin baik Word Of Mouth yang disampaikan konsumen maka akan meningkatkan Impulse Buying Minyak Kutus-Kutus Di Denpasar.

Word Of Mouth (WOM) atau komunikasi dari mulut ke mulut merupakan proses komunikasi yang berupa pemberian rekomendasi baik secara individu maupun kelompok terhadap suatu produk atau jasa yang bertujuan untuk memberikan informasi secara personal (Kotler dan Keller, 2012). Strategi pemasaran ini lebih terlihat simpel dan tidak membutuhkan biaya yang besar, namun memiliki tingkat efektif yang cukup besar terhadap Impulse Buying.

Hasil penelitian ini konsisten dengan penelitian yang dilakukan Diyos Nugraha Eka Putra (2015) yang menghasilklan simpulan bahwa Word Of Mouth berpengaruh terhadap Impulse Buying pada Cafe Roti Gempol dan Kopi Anjis. Selain itu penelitian Finnan Aditya Ajie Nugraha, Suharyono, Andriani Kusumawati (2015) juga menghasilkan simpulan bahwa variabel Word Of Mouth berpengaruh signifikan terhadap variabel Impulse Buying.

2) Pengaruh Visual Merchandising Secara Parsial Terhadap Impulse Buying pada produk Minyak Kutus-Kutus di Denpasar

Berdasarkan Tabel dapat diketahui pengaruh Visual Merchandising secara parsial terhadap Impulse Buying menghasilkan nilai signifikansi $0,000<0,05$ dengan nilai koefisien beta positif. Hasil tersebut mendukung hipotesis $(\mathrm{H} 2)$ yaitu Secara parsial Visual Merchandising berpengaruh positif terhadap Impulse Buying. Hal ini berarti bahwa semakin menarik Visual Merchandising maka akan meningkatkan Impulse Buying Minyak Kutus-Kutus Di Denpasar.

Visual merchandising ialah teknik dalam mempresentasikan tampilan barang dagangan sangat menarik (eye-catching) dan ditujukan pada pelanggan potensial (Jain et al., 2012). Dengan demikian, setiap toko mencoba untuk meningkatkan citra toko dengan komoditas yang menarik bagi pelanggan dan membuat pelanggan setia kepada merek tersebut sehingga mendorong perilaku pembelian. 
Hasil penelitian ini konsisten dengan penelitian Ismah Muthiah, Dian A.S Parawansa, Abdul Razak Munir (2018) yang menjelaskan bahwa variabel Visual Merchandising memiliki pengaruh positif dan signifikan terhadap variabel pembelian impulsif konsumen Matahari Department Store di Makassar.

3) Pengaruh Creative Promotion Secara Parsial Terhadap Impulse Buying pada produk Minyak Kutus-Kutus di Denpasar

Berdasarkan Tabel dapat diketahui pengaruh Creative Promotion secara parsial terhadap Impulse Buying menghasilkan nilai signifikansi $0,000<0,05$ dengan nilai koefisien beta positif. Hasil tersebut mendukung hipotesis $(\mathrm{H} 3)$ yaitu secara parsial Creative Promotion berpengaruh positif terhadap Impulse Buying. Hal ini berarti bahwa semakin baik Creative Promotion maka akan meningkatkan Impulse Buying Minyak Kutus-Kutus Di Denpasar.

Promosi yang kreatif menggunakan strategi komunikasi pemasaran terpadu yaitu suatu sinergi, kreativitas, integrasi, dan komunikasi pemasaran dengan cara memanfaatkan beragam elemen komunikasi yang berbeda-beda agar tercipta koherensi yang saling mendukung (Freddy Rangkuti, 2009).

Hasil penelitian ini konsisten dengan penelitian Doni Hariadi (2013) yang menyimpulkan bahwa variabel promosi berpengaruh positif terhadap Impulse Buying pada Produk Projector Microvision.

4) Pengaruh Word Of Mouth, Visual Merchandising dan Creative Promotion Secara Simultan Terhadap Impulse Buying pada produk Minyak Kutus-Kutus di Denpasar

Berdasarkan Tabel dapat diketahui pengaruh Word Of Mouth, Visual Merchandising dan Creative Promotion secara simultan terhadap Impulse Buying menghasilkan nilai signifikansi $0,000<0,05$ dengan nilai positif. Hasil tersebut mendukung hipotesis $(\mathrm{H} 4)$ yaitu secara simultan Word Of Mouth, Visual Merchandisin dan Creative Promotion berpengaruh positif terhadap Impulse Buying. Hal ini berarti bahwa Word Of Mouth, Visual Merchandising dan Creative Promotion secara bersama-sama mampu mempengaruhi peningkatan Impulse Buying Minyak Kutus-Kutus Di Denpasar.

Word of mouth menjadi media yang paling kuat dalam mengomunikasikan produk atau jasa kepada dua atau lebih konsumen. Stimulus dalam lingkungan berbelanja dapat diwujudkan dengan menggunakan Visual Merchantdise, seperti penataan produk, pemilihan warna yang indah untuk gerai, pencahayaan di dalam toko yang akan memudahkan konsumen melihat produk dengan jelas, serta keragaman produk akan membuat konsumen nyaman berbelanja yang dapat menyebabkan terjadinya Impulse Buying. Creative Promotion atau bauran promosi adalah paduan spesifik periklanan, promosi penjualan, hubungan masyarakat, dan penjualan personal, dan sarana pemasaran langsung yang digunakan perusahaan untuk mengkomunikasikan nilai konsumen secara persuasif dan membangun hubungan konsumen. Oleh karena itu, apabila Word Of Mouth, Visual Merchandising dan Creative Promotion yang berjalan dengan baik akan menentukan Impulse Buying Minyak Kutus-Kutus Di Denpasar.

\section{SIMPULAN}

Berdasarkan hasil penelitian yang telah diuraikan, maka simpulan yang berkaitan dengan Pengaruh Word Of Mouth, Visual Merchandising dan Creative Promotion terhadap Impulse Buying Minyak Kutus-Kutus Di Denpasar adalah sebagai berikut:

1) Word Of Mouth berpengaruh positif terhadap Impulse Buying Minyak Kutus-Kutus Di Denpasar dengan nilai signifikan sebesar $0,000<0,05$. Hal ini berarti bahwa semakin baik Word Of Mouth yang disampaikan konsumen maka akan meningkatkan Impulse Buying Minyak Kutus-Kutus Di Denpasar.

2) Visual Merchandising berpengaruh positif terhadap Impulse Buying Minyak Kutus-Kutus Di Denpasar dengan nilai signifikan sebesar $0,000<0,05$. Hal ini berarti bahwa semakin 
menarik Visual Merchandising maka akan meningkatkan Impulse Buying Minyak KutusKutus Di Denpasar.

3) Creative Promotion berpengaruh positif terhadap Impulse Buying Minyak Kutus-Kutus Di Denpasar dengan nilai signifikan sebesar $0,000<0,05$. Hal ini berarti bahwa semakin baik Creative Promotion maka akan meningkatkan Impulse Buying Minyak Kutus-Kutus Di Denpasar.

4) Secara simultan Word Of Mouth, Visual Merchandisin dan Creative Promotion berpengaruh positif terhadap Impulse Buying Minyak Kutus-Kutus Di Denpasar dengan nilai signifikan sebesar $0,000<0,05$. Hal ini berarti bahwa semakin baik Word Of Mouth, Visual Merchandising dan Creative Promotion yang diimplementasikan oleh perusahaan maka akan meningkatkan Impulse Buying Minyak Kutus-Kutus Di Denpasar.

\section{Saran}

Berdasarkan pembahasan hasil penelitian dan simpulan maka saran yang dapat diberikan adalah sebagai berikut:

1) Bagi Perusahaan Minyak Kutus-Kutus Di Denpasar

Untuk perusahaan disarankan agar senantiasa menjaga kualitas dan kuantitas produk minyak kutus-kutus sehingga Word Of Mouth berjalan dengan baik dan memberikan efek yang positif bagi perusahaan.

Perusahaan juga perlu secara progresif memperbaharui Visual Merchandising agar mampu mempertahankan konsumen minyak kutus-kutus dan sebagai salah satu strategi untuk memenangkan pasar produk obat herbal.

Selain itu, pemasaran minyak kutus-kutus perlu ditingkatkan secara konsisten dengan berbagai Creative Promotion sehingga dapat meningkatkan minat calon konsumen untuk membeli minyak kutus-kutus di Denpasar.

2) Bagi penelitian selanjutnya

Adapun keterbatasan dalam penelitian ini adalah penelitian ini hanya menggunakan variabel bebas yaitu Word Of Mouth, Visual Merchandising dan Creative Promotion sehingga diharapkan penelitian selanjutnya menambahkan variabel yang mampu meningkatkan Impulse Buying seperti Harga, Display Product, dan Store Atmosphere. Selain itu, penelitian ini menggunakan teknik analisis regresi linear berganda sehingga untuk peneliti selanjutnya bisa menggunakan teknik analisis yang berbeda. Saran lainnya adalah mengenai ruang lingkup penelitian yang hanya dilakukan di wilayah Denpasar, dan diharapkan untuk penelitian selanjutnya lebih mengembangkan lokasi penelitian.

\section{REFERENSI}

Arikunto, S. 2013. Prosedur Penelitian: Suatu Pendekatan Praktik.Jakarta: Rineka Cipta.

Engel, James F., Roger D. Blackwell dan Paul W. Miniard. 2000. Perilaku Konsumen, Jilidl, Jakarta: Bina Rupa Aksara.

Fam, K. S., Merrilees, B., Richard, J. E., Jozca, L., Li, Y., and Krisjanous, J. 2011. In-store marketing: a strategic perspective, Asia Pasific. Journal of Marketing and Logistics, 23.2. 165- 176. ISSN: 1355-5855.

Fring, G.S. 2014. Fashion: from concept to customer 9th edition. Edinburg Gate Harlow: Pearson Education Limited.

Ghozali, Imam. 2011. "Aplikasi Analisis Multivariate Dengan Program SPSS”. Semarang: Badan Penerbit Universitas Diponegoro.

Ghozali, Imam. 2013. Aplikasi Analisis Multivariate dengan Program IBM SPSS 21 Update PLS Regresi, Badan Penerbit Universitas Diponegoro, Semarang.

Ghozali, Imam. 2016. Aplikasi Analisis Multivariate dengan Program SPSS. Edisi 8. Semarang: Universitas Diponogoro.

Hasan, Ali. 2010. Marketing Dari Mulut ke Mulut: Word of Mouth Marketing. Jakarta: Media Pressindo (MedPress). 
Indriantoro, Nurdan Bambang Supomo. 2002. Metodologi Penelitian Bisnis : Untuk Akuntasi dan Manajemen, Yogyakarta: BPFEE.

Jain, V., Sharma, A., Narwal, P. 2012. Impact of visual merchandising on consumer behavior towards women's apparel.International Jour-nal of Research In Management, 5.2.

Kotler, Philip \& Keller. 2012. Marketing Management, 14th Edition. New Jersey: PrenticeHall.

Lupiyoadi,H. 2006. Manajemen Pemasaran Jasa. Jakarta: Penerbit Salemba Empat.Maymand, Mohammad M., dan Ahmadinejad, M. (2011). Impuls Buying: The Role of Store Environmental Stimulation and Situasional Factors (An Empirical Investigation). African Journal of Business Management 5, 13057- 13065. ISSN:1993-8233.

Nasution. 2009. Metode Research (Penelitianllmiah). Jakarta: Bumi Aksara.

Nugroho, A. Y. 2011. It's Easy Olah Data Dengan SPSS, Skripta Media Creative Yogyakarta.

P.Joko Subagyo. 2011. Metodologi Penelitian Dalam Teori Dan Praktek.Jakarta : Aneka Cipta.

Samuel, H. 2005. Respons Lingkungan Berbelanja Sebagai Stimulus Pembelian Tidak Terencana pada Toko Serba Ada (Toserba), Jurnal Manajemen dan Kewirausahaan, 7.2., 152-170.

Santoso, Singgih. 2012. Analisis SPSS pada Statistik Parametrik, PT. Elex Media Komputindo, Jakarta.

Sernovitz, Andi. 2009. Word of Mouth Marketing: How Smart Companies Get People Talking.New York: Kaplan.

Setiadi, Nugroho. 2008. Perilaku Konsumen. Jakarta: Kencana Prenada Media Group.

Sugiyono. 2011. Metode Penelitian Kombinasi (Mixed Method). Bandung: Alfabeta.

Sugiyono. 2013. Metode Penelitian Kuantitatif Kualitatif dan $R \& D$, Alfabeta,Bandung.

Sugiyono. 2016. Metode Penelitian Kuantitatif, Kualitatif dan R \& amp;D. Bandung: PT Alfabet.

Sumardy. 2011. The Power of Word of Mouth. Jakarta: PY. Gramedia Pustaka Utama.

Supriyati. 2011. Metodologi Penelitian. Bandung: Labkat press.

Tjiptono dan Irawan. 2012. Total Quality Manajemen, Yogyakarta :Andi Offset. 